\title{
College Students' Prevalence of Sleep Hygiene Awareness and Practices
}

\author{
Victoria A. Felix \\ Department of Psychology and Behavioral Sciences, Louisiana Tech University \\ Nathalie A. Campsen \\ Department of Psychology and Behavioral Sciences, Louisiana Tech University \\ Abbey White \\ Department of Graduate Counseling, John Brown University \\ Walter C. Buboltz \\ Department of Psychology and Behavioral Sciences, Louisiana Tech University
}

\begin{abstract}
Research has consistently found that college students report short sleep length and poor sleep quality. As a result of their poor sleep quality, there is concern that college students may struggle with issues associated with academic performance, physical health, and mental health. Previous research has investigated a multitude of factors that may contribute to poor sleeping behaviors, including sleep hygiene awareness and practices. The current study found that participants were obtaining less than the recommended average hours of sleep. Results indicated an almost equal number of participants reported poor sleep quality, average sleep quality, and good sleep quality. Results also indicated that between $40-50 \%$ of the sample reported difficulties related going to bed, falling asleep, maintaining sleep, reinitiating sleep, and returning to wakefulness. Although participants in the present study reported sleep hygiene awareness, their knowledge is not associated with their sleep practices. Based on these results, it may be implied that improving or increasing sleep hygiene knowledge is not an intervention that would be effective in improving sleep hygiene practices.
\end{abstract}

Keywords: sleep prevalence, college students, sleep hygiene practices, sleep quality, sleep length

\section{College Students' Prevalence of Sleep Hygiene Awareness and Practices}

The National Sleep Foundation (2015) recommends that college students receive seven to nine hours of sleep every night. However, results from a National Sleep Foundation (2015) survey supported that over half of the 19-29 year-old participants are not receiving this recommended amount of sleep. Previous research has found similar results, with college students reporting poor sleep quality and short sleep length, with specific problems related to receiving adequate sleep on weeknights (Lund, Reider, Whiting, \& Prichard, 2010). Additionally, college students have reported fewer hours of sleep on weekdays than on weekends, as well as oversleeping on most weekends (Ari \& Shulman, 2013; Buboltz, Jenkins, Soper, Woller, Johnson, \& Fans, 2009; Forquer, Camden, Gabriau, \& Johnson, 2008; Lund et al., 2010). With supportive research findings of reported limited sleep length and poor sleep quality amongst college students, it is necessary to consider what factors may be contributing to poor sleep. 
Based on previous research findings, college students may not be obtaining the recommended seven to nine hours of sleep due to poor sleep quality (Buboltz, Brown, \& Soper, 2001). Sleep quality has been defined as a measure of how long it takes to fall asleep, reported hours remaining asleep, the frequency of sleep disturbances, the use of sleep medication, and reports of daytime sleepiness (Buysse, Reynolds, Monk, Berman, \& Kupfer, 1989). Research consistently supports that college students experience sleep difficulties. For example, Lund et al. (2010) found that $70.6 \%$ of the college students in their sample reported that they did not receive at least eight hours of sleep every night. Furthermore, only $40 \%$ of the participants reported sleeping without disturbances. In addition, $20 \%$ of the students indicated that they remained awake all night at least once per month and 35\% acknowledged staying awake until 3 A.M. at least once per week (Lund et al., 2010). Similarly, Buboltz et al. (2001) found that $73 \%$ of college students reported poor sleep quality, specifically noting that the most prevalent sleep difficulties were requiring more than 30 minutes to fall asleep, morning tiredness, waking up too early, and having difficulties falling asleep more than three times per week. An expanded study also found that a majority of participants $(88.5 \%)$ reported occasional sleep difficulties, with $54.4 \%$ reporting morning tiredness and $74.3 \%$ acknowledging that they do not get enough sleep during the week (Buboltz et al., 2009).

Furthermore, Vail-Smith, Michael Felts, and Becker (2009) found that 77\% of their sample reported experiencing sleep difficulties. Among a sample of college students from Hong Kong, $57.5 \%$ of the sample reported poor sleep quality, noting later bedtimes, shorter sleep length, longer daytime sleep, napping, and higher levels of perceived fatigue (Suen, Hon, \& Tam, 2008). Forquer et al. (2008) found that $33 \%$ of college students in their sample reported a 30 -minute time delay to fall asleep, while $43 \%$ of the college students reported waking up more than once during the night. Based on these research findings, it is evident that college students are not receiving quality sleep or the necessary recommended amount of sleep.

Research has found that college students, on average, sleep approximately seven hours, while $25 \%$ of students in that sample reported sleeping less than 6.5 hours a night and only $29.4 \%$ reported sleeping eight or more hours a night (Lund et al., 2010). Similarly, Israeli college students reported obtaining less than eight hours of sleep on average per night (Ari \& Shulman, 2013). Additionally, college students have reported receiving more sleep on weekends than on weeknights (Ari \& Shulman, 2013; Buboltz et al., 2009; Forquer et al., 2008; Lund et al., 2010). More specifically, college students reported going to sleep one hour later on weekends than on weeknights, as well as waking one and a half to two hours later on the weekends than on weeknights (Ari \& Shulman, 2013; Buboltz et al., 2009; Forquer et al., 2008). Interestingly, research has also found significant differences between perceived sleep and ideal sleep for both weekdays and weekends among college students. This indicates that there are differences between the amount of sleep college students report obtaining, and the amount of sleep they believe is most beneficial (Buboltz et al., 2001).

Poor sleep quality and sleep length can often times lead to the development of insomnia (Mayo Clinic Staff, 2014). Insomnia is defined as a persistent complaint of difficulty in initiating or maintaining sleep or early-morning awakening with an inability to return to sleep, and is associated with functional impairments in social and occupational areas (American Psychiatric Association, 2013). According to Morin, Kowatch, Barry, and Walton (1993), insomnia effects approximately $30-40 \%$ of the general population. More specifically, $37 \%$ of research participants, ranging in age from 16 years old to 74 years old, reported insomnia symptoms, with $12 \%$ of participants reporting moderate to severe symptoms (Stewart et al., 2006). Insomnia was also found to be associated with reported fatigue and poorer health-related 
quality of life (Stewart et al., 2006). Additionally, previous research has found that individuals who reported experiencing insomnia symptoms also reported moderate depressive symptoms and increased arousal in comparison to individuals who reported that they were good sleepers (LeBlanc et al., 2007).

While $30-40 \%$ of the general population reports experiencing insomnia symptomology, research findings indicate that there is a higher prevalence of insomnia among the college student population. For example, Sing and Wong (2010) found that 68.6\% of a Hong Kong college student sample reported symptoms of insomnia. Gress-Smith, Roubinov, Andreotti, Compas, and Luecken (2015) found that one-fourth of their participants reported experiencing mild to severe levels of insomnia, with 29\% reporting clinically significant concurrent depressive symptoms and mild to severe insomnia. Additionally, previous studies have found that between 50 and 60 percent of college students were experiencing insomnia symptoms (Lund et al., 2010; Sadigh, Himmanen, Scepansky, 2014). College students who also endorsed higher levels of insomnia severity were also found to be more likely to participate in improper sleep scheduling, report uncomfortable sleeping environments, and engage in arousing behaviors prior to bedtime (Gellis, Park, Stotsky, \& Taylor, 2014).

More specifically, previous research has found that $26.9 \%$ of college student participants met the severity, frequency, and duration criteria of insomnia, 9.5\% met the diagnosis of chronic insomnia, and 6.5\% reported an insomnia complaint but did not meet the severity, frequency, and duration criteria required for a diagnosis of insomnia (Taylor, Bramoweth, Grieser, Tatum, \& Roane, 2013). It was also found that females (15.7\%) were more likely than males (9.9\%) to meet the diagnostic criteria for chronic insomnia (Taylor et al., 2013). Similar results were also found in a sample of Saudi Arabian female college students, with 42\% of participants reporting sub-threshold insomnia and 8\% reported moderate clinical insomnia (Al-Eisa et al., 2013). College students whom met the diagnostic criteria for chronic insomnia also reported increased levels of depression, anxiety, stress, and fatigue, as well as a decreased quality of life (Taylor et al., 2013).

Another area of concern regarding the sleep behaviors of college students is their sleep preferences, more specifically whether they prefer the morning or evening. People with morning preferences prefer to go to bed earlier in the evening and wake up earlier in the morning, while people with evening preferences prefer to go to bed later in the evening and wake up later in the day (Schneider et al., 2011). Such preferences are also known as circadian phase preferences, which are often associated with daily peak times of alertness, performance, and body temperature (Taylor, Clay, Bramoweth, Sethi, \& Roane, 2011). Morningnesseveningness preferences may also provide explanations for poor sleep quality (Schneider et al., 2011). People with morning preferences prefer to go to bed earlier in the evening and wake up earlier in the morning, while people with evening preferences prefer to go to bed later in the evening and wake up later in the day (Schneider et al., 2011).

Previous research has found that female college students had a higher prevalence of morning preference in comparison to male college students (Taylor et al., 2011). It was also found that senior college students were more likely to report morning preferences than freshman college students (Taylor et al., 2011). Additionally, the National Sleep Foundation has found that $41 \%$ of adults consider themselves to be evening people, while $55 \%$ of adults consider themselves to be morning people (National Sleep Foundation, 2005). Numerous previous studies have shown that morning-typed individuals are generally healthier and at less of a risk for physical, psychological, and psychosomatic distresses as opposed to those who are evening-typed individuals (Cavallera \& Giudici, 2007; Gianotti, Cortesi, Sebastiani, \& Ottaviano, 2002; Mecacci 
\& Rocchetti, 1998). Morning-typed individuals tend to have higher levels of self-regard, possessing greater self-esteem and conscientiousness (Jackson \& Gerard, 1996). Furthermore, morning-typed individuals tend to possess a more realistic and analytical personality style (Diáz-Morales, 2007).

Evening-typed individuals seem to have greater issues with psychological distress, such as depression (Chelminski, Ferraro, Petros, \& Plaud, 1999; Gianotti et al., 2002; Takeuchi et al., 2002) and anxiety (Matthews, 1986; Mecacci \& Rocchetti, 1998; Nebel et al., 1996; Taillard, Philip, Chastang, Diefenbach, \& Bioulac, 2001; Willis, O'Connor, \& Smith, 2005), and are overall less satisfied with their quality of life (Randler, 2007). These findings have led some to believe that morning-typed individuals are generally stable people (DeYoung, Hasher, Djikic, Criger, \& Peterson, 2007), where evening-typed individuals may not be able to appropriately cope with the societal demands (Adan, 1994; Monk, Buysse, Potts, DeGrazia, \& Kupfer, 2004). The array of issues surrounding evening-typed individuals and its effects on quality of sleep can be detrimental to several different areas of those people's lives.

Upon beginning college, college students are faced with transferring from inflexible school schedules and parental restraint to increased flexibility in their schedules and a lack of dependence on parents (Zimmermann, 2011). A change in daily schedules allows for students to sleep longer in the morning, and to go to bed later in the evening without a need to decrease the amount of sleep (Zimmermann, 2011). This allows for evening-typed students to align their scheduling appropriately and comfortably with their sleep and wake patterns (Zimmermann, 2011). Despite this, few evening-typed students reported receiving greater than seven hours of sleep per night, which has often been compensated with longer and more frequent naps during the day when compared to morning-typed students (Zimmermann, 2011). Evening-typed students also reported remaining asleep until the last moment, consuming more caffeinated beverages, and going to bed earlier when having to cope with morning scheduled events in comparison to morning-typed students (Digdon \& Rhodes, 2009; Zimmermann, 2011).

Generally, people who have morning preferences are likely to be more alert and have better performance earlier in the day, while people with evening preferences are more alert and productive later in the evening (Schneider et al., 2011). Students' morningness-eveningness preferences may also provide explanations for poor sleep quality (Schneider et al., 2011). Among their sample of college students, Schneider et al. (2011) found that 39.5\% of the participants identified as evening types. Results also supported that students reporting evening preferences were more likely to report poor sleep quality (Schneider et al., 2011). These poor sleep hygiene practices may lead to poor sleep quality for students with evening preferences (Digdon \& Rhodes, 2009). While minimal research exists on morning-evening preferences and sleep quality, research supports the relationship between the two variables. Knowing that evening preferences can negatively impact sleep quality, there is concern for how such a relationship can impact other aspects of a college student's life.

As a result of their poor sleep quality, college students may struggle with issues associated with academic performance, physical health, and mental health (Gilbert \& Weaver, 2010; Howell, Jahrig, \& Powell, 2004; Lund et al., 2010; Orzech, Salafsky, \& Hamilton, 2011). Therefore, it is important to consider the ways in which poor sleep quality can impact various aspects of a college student's life. 


\section{Sleep and Mental Health}

Previous research has found that students who reported experiencing anxiety or depressive symptoms within an academic year also reported poorer sleep quality in comparison to those students who did not report experiencing depression or anxiety (Orzech et al., 2011). Additionally, students who reported experiencing interpersonal conflict within an academic year also experienced poor sleep quality (Orzech et al., 2011). College students who report symptoms of insomnia are at an increased risk to suffer from depression and substance abuse (Roane \& Taylor, 2008). Furthermore, Zawadski, Graham, and Gerin (2012) found that the relationship between depression and sleep quality was mediated by reports of loneliness and rumination among college students. Individuals who experience loneliness are less likely to resolve issues through the use of social relationships, which may contribute to repeated rumination and a reoccurring experience of stress (Zawadski et al., 2012). These results produce concern regarding the mental health of college students who report poor sleep quality and length.

\section{Sleep and Academic Performance}

Tension and stress were also found to be impactful factors in predicting sleep quality, with $20.1 \%$ of students reporting that stress had interfered with sleep at least once per week (Lund et al., 2010). Additionally, when asked to rate psychological factors that negatively influence sleep, college students reported that stress accounted for $64.8 \%$ of the factors influencing sleep (Altun, Cinar, \& Dede, 2012). Similar results were found in a sample of female college students, in that their perception of overall stress was found to be significantly related to sleep disturbances, morning fatigue, less nocturnal total sleep time, and sleep disturbances (Lee, Wuertz, Rogers, \& Chen, 2013). Students who reported dedicating more time to completing schoolwork and/or reported having a test on the following day were also more likely to report poor sleep quality (Galambos et al., 2009). These findings support that academic stress can result in poor sleep quality, which may then also result in decreased academic performance.

Delayed sleep and poor sleep quality have been acknowledged as contributing factors in decreasing academic performance amongst college students (Eliasson, Lettieri, \& Eliasson, 2010). Research supports that students who stress and worry about academic performance may be more likely to experience poor sleep quality (Galambos, Dalton, \& Maggs, 2009; Lund et al. 2010). Trockel, Barnes, and Egget (2000) found that college students reporting later wakeup times were more likely to have lower grade point averages than students reporting earlier wake-up times. College students who identified as evening-types have also reported higher levels of fatigue, alcohol, tobacco, and caffeine use, and poor academic performance in comparison to their morning-types (Fernandez-Mendoza et al., 2010; Taylor et al., 2011). Specifically, evening-type college students acknowledged poorer memory, missing classes due to oversleeping or feelings of tiredness, falling asleep in class, and the perception of improved academic performance with an increase in sleep (Fernandez-Mendoza et al., 2010).

Previous research has also found that increased sleep quality resulted in an increase in college GPA (Orzech et al., 2011). College students also identified poor sleep as a factor that impacted their quality of schoolwork (Orzech et al., 2011). Similar results were found in that college students who reported getting more sleep before school or work and college students who reported consistent sleep schedules also indicated higher grades (Gaultney, 2010).

\section{Sleep and Physical Health}

With an adjustment in flexibility in scheduling of academic courses and rise/wake times, college students are also confronted with making decisions regarding their physical activity (Dinzeo et al., 2014). Beginning college is often associated with weight gain; however, research 
has found that with an increase in physical activity, college students have reported an increase in weight loss (Gropper et al., 2012). Previous research has also noted that regular exercise improves sleep length, sleep quality, reduced sleep onset delay, and improved sleep efficiency (Kredlow, Capozzoli, Hearon, Calkins, \& Otto, 2014). However, college students who reported an increase in physical exercise also expressed an increase in protective measures preventing depression, psychopathological symptoms, and poor sleep (Wu, Tao, Zhang, \& Tao, 2015).

Despite such findings, college students often overlook physical activity as an area of importance (Kredlow et al., 2014). With limited research reviewing the relationship between sleep and physical activity amongst college students, there is concern regarding the need to educate college students on the positive relationship between physical activity and sleep quality and sleep length.

It is also important to note that poor sleep quality has been found to contribute to various health issues (Holbrook, Crowther, Lotter, Cheng, \& King, 2000). For example, Costa (2003) conducted a study on a sample of non-standard-shift workers. Results indicated that the continuous circadian rhythm was associated with increases in somatic stress, which may be associated with decreases in physical health.This of particular interest when considering college students since the typical college student's schedule consists of irregularity and disruption of the body's circadian rhythm.

The relationship between poor sleep quality and poor sleep hygiene practices may provide further information regarding the possible factors contributing to inadequate sleep length and quality among samples of college students (Brown, Soper, \& Buboltz, 2001). Sleep hygiene practices are behaviors that can positively or negatively affect a person's sleep length and quality (Brown et al., 2006). Factors associated with a college student's lifestyle may provide an environment leading to poor sleep quality. With the adjustment to college, students are confronted with lifestyle factors associated with such adjustment including deciding the contents of a meal, sleep routines, the level of physical activity in which to engage, and alcohol and substance use (Dinzeo, Thayasivam, \& Sledjeski, 2014).

The social environment of the college lifestyle may lead to poor sleep hygiene practices. College students who report consuming alcohol are more likely to report instances of oversleeping and staying awake later on weekends than weekdays (Galambos et al., 2009; Singleton \& Wolfson, 2009). Stasio, Wagener, and Glassman (2011) found that $20 \%$ of the variance in sleep difficulties among a sample of college students was explained by reported energy drink consumption. Furthermore, research has reported that college students who consumed two or more stimulant beverages per week also reported poorer sleep quality in comparison to those students who consumed one stimulant beverage per week (Lohsoonthorn et al., 2013).

In addition to energy drink consumption, college students who engage in pathological text messaging behaviors (e.g., inability to reduce texting, mood changes and irritable mood if not able to text) are more likely to report poor sleep quality (White, Buboltz, \& Frank, 2011). Additionally, college students engaging in excessive mobile phone use also report poor sleep quality (Bianchi \& Phillips, 2005). Further, research conducted by Custers and Van den Bulck (2012) has shown that Internet use contributes to changes in bedtime and wake time, with later wake times over the weekend when an early wake time may not be required. Adults who have access to the Internet in their bedrooms tend to experience "time shifting" (Van den Bulck, 1999). "Time shifting" refers to when individuals compensate for extending their 
bedtime by changing their wake time. All of these activities may have drastic, deleterious effects on sleep quality and overall health.

With supportive research findings regarding college students and poor sleep quality and sleep length, there is a cause for concern as to whether or not college students are aware of how to improve their overall sleep length and sleep quality. Previous research examining sleep hygiene awareness practices and sleep hygiene knowledge found that proper sleep habits do not necessarily influence sleep quality, however, the practice of proper sleep habits is strongly related to good overall sleep quality (Brown, Buboltz, Soper, 2002). The use of sleep hygiene instruction as a form of intervention and prevention to improve sleep practices of college students has been supported an effective intervention (Brown et al., 2002). Increasing education regarding such practices may impact the active use of the practices, which may in turn improve the sleep quality of college students.

As research has found support that college students consistently report inadequate sleep length and poor sleep quality, previous research has investigated a multitude of factors that may contribute to poor sleeping behaviors. Some of these factors including sleep hygiene awareness and practices may provide explanations for college students' inadequate sleep length and quality (Buboltz et al., 2001; Lund, et al., 2010). The present study aims to investigate the prevalence rates of sleep hygiene awareness and sleep hygiene practices among a sample of college students. Through identifying the prevalence rates of sleeping behaviors associated with sleep quality, these results may provide further understanding about the possible sources of college students' poor sleep quality.

\section{Participants}

\section{METHOD}

There were 174 undergraduate introductory psychology students from a southern university who participated in this study. The mean age was 19.62 (SD = 3.97). The sample included almost an equal number of men and women, with 51.7\% men and $48.3 \%$ women. The sample was comprised of participants identifying as Caucasian (66.1\%), African American (25.3\%), Other (4\%), Asian American (2.9\%), Hispanic/Latino (1.1\%), and Native American (.6\%). The mean GPA of the participants was $3.13 \%(\mathrm{SD}=.86)$.

\section{Instruments}

Demographics. A demographics questionnaire was developed and included nine items asking the participants to report their age, gender, academic rank, relationship status, ethnicity, academic major, grade point average, housing situation, and living arrangement.

\section{Sleep Habits Survey (SHS, Brown, Buboltz, \& Soper, 2001).}

This scale includes 13 open-ended items that measure sleep length. In the present study, the items included in the analysis were "On the weekend, what time do you usually wake up?," "During the week, what is your average amount of sleep each night?," "It usually takes me about minutes to fall asleep on a weeknight," and "It usually takes me about minutes to fall asleep on a weekend night."

Adult Sleep-Wake Scale (ADSWS, Fortunato, LeBourgeois, \& Harsh, 2008).

This scale is comprised of 25 items with 5 subscales, including going to bed (e.g., "I want to stay up and do other things"), falling asleep (e.g., "I am unable to settle down"), maintaining sleep (e.g., "I toss and turn in bed"), reinitiating sleep (e.g., "I have a hard time going back to sleep"), 
and returning to wakefulness (e.g., "I am slow-to-start in the morning"). These items are measured on a 6-point Likert-type scale that ranges from 1 (never) to 6 (always).

The scale was found to have valid construct validity, as sleep dimensions correlated with positive and negative affectivity (dispositional variables); interpersonal conflict, workload, and job ambiguity (stressor variables); and depression, frustration, and health complaints (strain variables). The scale was also found to have adequate test-retest reliability, ranging from .67.82 .

In the present study, the total sleep quality score for this sample was divided into three groups including poor sleep quality, average sleep quality, and good sleep quality. Additionally, each subscale was divided into two groups (high vs. low scores) to provide more specific information about aspects of sleep quality that were most prevalent in this sample.

\section{Sleep Hygiene Awareness and Practices Scale (SHAPS, Lacks \& Rotert, 1986).}

SHAPS is separated into two sections, including sleep hygiene awareness and sleep hygiene practices. The Sleep Hygiene Awareness section consists of 18 sleeping behaviors that are rated from 1 (very beneficial to sleep) to 7 (very disruptive to sleep). A total sleep hygiene awareness score is determined by scoring responses to each item, with correct responses receiving 1 point, blank responses receiving two points, and incorrect responses receiving three points. Lower scores indicate better sleep hygiene awareness. This scale was found to have adequate test-retest reliability $(\mathrm{r}=.50, \mathrm{p}<.001)$ (Brown et al., 2002) and good reliability $(\alpha=.78)$ (Brown et al., 2002).

The Sleep Hygiene Practices section consists of 19 sleeping behaviors that are rated from 0 (never engaged in the behavior) to 7 (engage in the behavior on a daily basis). The responses are summed for a total scale score. Higher scores indicate poor sleep hygiene practices. This scale was found to have poor reliability, with a Cronbach's alpha of .55. This poor reliability may be explained by high variability in participants' responses, rather than poor reliability of the actual measure (Brown et al., 2002). This measure had good test-retest reliability $(r=.74, p$ $<$.001) (Brown et al., 2002).

In the present study, sleep hygiene awareness scores were separated into two groups including high scores (indicating more knowledge) and low scores. Frequencies for each item on the sleep practices scale were computed to provide in-depth information about the activities that may contribute to poor sleep quality among college students in this sample.

\section{PROCEDURE}

Researchers visited undergraduate introductory psychology courses to recruit participants. After explaining the purpose of the study, the researchers distributed paper informed consent forms and surveys. The consent form explained the purpose of the study, as well as the risks and benefits of participating. Participants were also informed that participation is voluntary, anonymous, and that the survey should take approximately 30 minutes to complete. After signing the consent form, participants were provided with the survey, and returned their completed surveys during their next class meeting. The instructors collected the surveys and returned them to the researchers.

\section{RESULTS}

Results indicated that the mean sleep length on weeknights of participants in this study was reported as 7.00 hours ( $S D=1.27$ ). Participants also reported that during the week, it took 
them an average of 26.23 minutes (SD $=25.29$ ) to fall asleep. Based on this sample, $34.9 \%$ of participants were categorized in the poor sleep length group, reporting between 4-6 hours of sleep on weeknights. Additionally, 34.9\% of participants were also categorized in the good sleep length group, reporting 8-13 hours of sleep per weeknight.

The mean sleep length on weekends was reported as 8.37 ( $\mathrm{SD}=1.80$ ). On weekends, participants reported an average of $22.56(\mathrm{SD}=24.41)$ minutes to fall asleep. Among this sample, $31.2 \%$ of participants reported poor sleep length on weekends (4-6 hours of sleep). Additionally, $29.4 \%$ of participants reported good sleep length on weekends (8-12 hours of sleep)

When analyzing sleep quality, results indicated that an almost equal number of participants reported poor sleep quality (33.3\%), average sleep quality (33.9\%), and good sleep quality (32.8\%). Frequency information was also comprised for each subscale of sleep quality. Almost half $(47.7 \%)$ of participants in this sample reported that it is difficult for them to go to bed, $52.6 \%$ reported difficulty falling asleep, $44.3 \%$ reported difficulty maintaining sleep, 52.3\% reported difficulty reinitiating sleep, and $55.2 \%$ reported difficulty returning to wakefulness.

When analyzing sleep hygiene awareness, participants were separated into groups based on their total score. Higher scores indicate better sleep hygiene awareness knowledge. Results of this study indicated that $37.4 \%$ of participants have good sleep hygiene knowledge, 36.8\% of participants have average sleep hygiene knowledge, and $25.9 \%$ have poor sleep hygiene knowledge. Frequency data for each item of the sleep hygiene practices scale was also computed. Participants were asked to report the average number of days per week that they engaged in certain healthy or unhealthy sleep hygiene practices. Based on these results, $64.5 \%$ of participants reported that they drink caffeinated beverages within 4 hours of bedtime at least one night a week but up to 7 nights per week. Additionally, $12.1 \%$ of participants reported drinking more than 3 ounces of alcohol within 2 hours of bed at least one night a week, and $10.3 \%$ reported twice a week. Almost half (49.4\%) of participants in this sample reported worrying about their ability to sleep while preparing for bed at least one night per week. Additionally, $44.3 \%$ of participants reported engaging in strenuous exercise within 2 hours of going to bed. Over half (54.6\%) of participants in this sample reported that at least one night per week their sleep was disturbed by noise. Only $14.5 \%$ of participants reported that they go to bed at the same time every night for 7 days of the week.

\section{DISCUSSION}

The purpose of the present study was to investigate the prevalence of various sleeping behaviors and preferences among a sample of college students. There has been a consistent trend in prevalence statistics supporting that college students report short sleep length and poor sleep quality (Brown et al., 2001; Lund et al., 2010). While the National Sleep Foundation (2015) recommends that college students should obtain seven to nine hours of sleep, the current study found that $34.9 \%$ of the participants only obtained between four to six hours of sleep on weeknights. Additionally, $31.2 \%$ of the participants were categorized in the short sleep length group for obtaining between four to six hours of sleep on weekends. These findings indicate that college students are still having difficulty obtaining the recommended number of hours of sleep per night. Furthermore, participants in this sample reported a mean sleep length of 7 hours per night on weeknights and 8.37 hours per night on weekends. Coupled with poor sleep quality, these results imply that participants in this sample are likely experiencing symptoms of Delayed Sleep Phase Syndrome (DSPS), which includes symptoms of getting less sleep during the week and normal sleep on weekends (Weitzman et al., 1981). The results of the present study are consistent with previous research findings that college 
students report symptoms of DSPS especially as they transition into an independent lifestyle (Brown et al., 2001).

Similar results were found when analyzing reported sleep quality. Results indicated that between $40-50 \%$ of the sample reported difficulties in each of the following subscales of the ASWS (Fortunato et al., 2008), including difficulty going to bed, falling asleep, maintaining sleep, reinitiating sleep, and returning to wakefulness. Notably, $55.2 \%$ of the participants reported difficulty with returning to wakefulness. This indicates that college students may have difficulty with managing a college lifestyle and balancing responsibilities at school including early morning class times. If college students are having difficulty with getting good quality sleep during the night, coupled with short sleep length, it would make sense that they report the most difficulty with returning to wakefulness. These results were also in line with previous results with more than half of the sample of college students reported poor sleep quality (Kenney, Paves, Grimaldi, \& LaBrie, 2014).

Previous studies have hypothesized that sleep hygiene knowledge would predict sleep hygiene practices, expecting that participants with higher scores on sleep hygiene knowledge would be more likely to engage in healthy sleep hygiene practices (Felix, Gremillion, \& Buboltz, 2015). Findings are not supporting this hypothesis, indicating that while participants may report sleep hygiene awareness, their knowledge is not associated with their practices. Similar results were found in this study, with $74.2 \%$ of participants reporting average to good sleep hygiene knowledge, while over half of the sample reported engaging in unhealthy sleep hygiene practices including drinking caffeinated beverages, worrying about sleeping, engaging in strenuous exercise before bed, being disturbed by noise, and going to bed at different times every night. These findings are similar to previous research findings that college students report poor sleep quality associated with behaviors including drinking caffeinated beverages and becoming overwhelmed with worry and stress (Lee et al., 2013; Lohsoonthorn et al., 2014).

Based on these results, it may be implied that improving or increasing sleep hygiene knowledge is not an intervention that would be effective in improving sleep hygiene practices. College students with average to good sleep hygiene awareness are still reporting engaging in unhealthy sleep hygiene practices, implying that the knowledge is not a strong deterrent from engaging in these behaviors. Furthermore, there was still about $30 \%$ of the sample falling into the poor sleep hygiene awareness category. These results have important implications for sleep health education and promotion, indicating that individuals are not retaining this information and/or applying it to their lifestyles. Interventions for sleep hygiene practice may focus specifically on implementing and practicing behavioral changes rather than focusing solely on teaching sleep hygiene awareness. Additionally, interventions in a group setting with other peers who are also learning how to practice healthy sleep hygiene may be an enhancing component that increases social support as well as additional peer knowledge regarding their experiences with the interventions.

Future research and interventions should focus on the importance of practicing healthy sleep hygiene, especially among samples of college students. While healthy sleep has important benefits for academic performance, physical health, and emotional well-being, it is also important to highlight the role of sleep in mental health. Recently, there has been an increase in reported number and severity of mental health issues at college counseling centers and among campus communities. As research consistently supports the role of unhealthy sleep in exacerbating mental health difficulties (Zawadzki, Graham, \& Gerin, 2013), it may be important 
for college counseling centers, residential life directors, and orientation programs to include information about the importance of healthy sleep and offer services to increase healthy sleeping behaviors as a potential buffer against the exacerbation of mental health symptoms.

Research and interventions should also target behavioral factors that are specific to college students and their lifestyles on campuses. College students may benefit from interventions that teach and promote healthy sleeping behaviors, while also incorporating stress and time management workshops, mindfulness exercises, and coping and social skills trainings. These types of interventions would attend to the dynamic needs of college students as they adjust to the social and academic demands and pressures on campuses. Furthermore, information related to excessive use of text-messaging, social media sites including Facebook and Twitter, and browsing the Internet on mobile phones and tablets should also be included in the current sleep hygiene education manuals. As the use of technology, especially among this generation, continues to increase researchers are presented with ample opportunities to challenge individuals to engage in healthy sleeping behaviors.

These implications also provide important information for treatment approaches within University counseling centers. Group therapy settings that balance providing psychoeducation about healthy sleep integrated with behavioral interventions for healthy sleep may make a significant difference in improving sleep health. Behavioral interventions may include asking group members to keep a sleep diary to monitor sleep hygiene during the day and at night, provide sleep monitoring devices to consistently track sleep hygiene and pinpoint difficulties, develop individualized stimulus control sleep plans, and engage in using a worry time or writing in a journal to target ruminative thoughts that may increase wake time. Based on the reviewed literature, current findings, and implications, further research may be focused on developing and implementing a behavioral-focused intervention group for college students reporting sleep difficulties.

\section{Reference}

Adan, A. (1994). Chronotype and personality factors in the daily consumption of alcohol and psychostimulants. Addiction, 89, 455-462. doi:10.1111/j.1360-0443.1994.tb00926.x

Al-Eisa, E., Buragadda, S., Melam, G. R., Al-Osaimi, A., Al-Mubarak, H. A., \& Al-Huwaimel, N. A. (2013). Association between physical activity and insomnia among Saudi female college students. Journal of Physical Therapy Science, 25, 1479-1482. doi:10.1589/jpts.25.1479

Altun, I., Cinar, N., \& Dede, C. (2012). The contributing factors to poor sleep experiences in according to the university students: A cross-sectional study. Journal of Research in Medical Sciences, 17(6), 557-561. Retrieved from: http://jrms.mui.ac.ir/index.php/jrms/article/view/8491

American Psychiatric Association. Diagnostic and Statistical Manual of Mental Disorders (DSM-V). Washington D.C.: Author.

Ari, L. L. \& Shulman, S. (2013). Sleep, daily activities, and their association with mood states among emerging adults. Biological Rhythm Research, 44, 35-367. doi:10.1080/09291016.2012.692251

Bianchi, A. \& Phillips, J. G. (2005). Psychological predictors of problem mobile phone use. CyberPsychology and Behavior, 8, 39-51. doi:10.1089/cpb.2005.8.39

Bliwise, D.L., King, A., Harris, R., Hakell, W. (1992). Prevalence of self-reported poor sleep in a healthy population aged 50-65. Social Science and Medicine, 34, 49-55. doi:10.1016/0277-9536(92)90066-y

Brown, F. C., Buboltz, W. C., Jr., Soper, B. (2002) Relationship of sleep hygiene awareness, sleep hygiene practices, and sleep quality in university students. Behavioral Medicine, 28, 33-38. doi:10.1080/08964280209596396 
Felix, V. A., Campsen, N. A., White, A., \& Buboltz, W. C. (2017). College Students' Prevalence of Sleep Hygiene Awareness and Practices. Advances in Social Sciences Research Journal, 4(4) 91-105

Brown, F. C., Soper, B., \& Buboltz, W. C., Jr. (2001). Prevalence of delayed sleep phase syndrome among university students. College Student Journal, 35, 472-476.

Buboltz, W. C. Jr., \& Brown, F. C., \& Soper, B. (2001). Sleep habits and patterns of college students: A preliminary study. Journal of American College Health, 50, 131-135. doi:10.1080/07448480109596017

Buboltz, W., Jr., Jenkins, S. M., Soper, B., Woller, K., Johnson, P., \& Fans, T. (2009). Sleep habits and patterns of college students: An expanded study. Journal of College Counseling, 12, 113-124. doi:10.1002/j.21611882.2009.tb00109.x

Buysse, D. J., Reynolds, C. F., III, Monk, T. H., Berman, S. R., \& Kupfer, D. J. (1988). The Pittsburgh sleep quality index: A new instrument for psychiatric practice and research. Psychiatry Research, 28, 193-213.

doi:10.1016/0165-1781(89)90047-4

Cavallera, G. M., \& Giudici, S. (2007). Morningness and eveningness personality: A survey in literature from 1995 up till 2006. Personality and Individual Differences. 44, 3-21. doi:10.1016/j.paid.2007.07.009

Chelminski, I., Ferraro, F. R., Petros, T. V., \& Plaud, J. J. (1999). An analysis of the "eveningness-morningness" dimension in "depressive" college students. Journal of Affective Disorders. 52, 19-29. doi:10.1016/s01650327(98)00051-2

Costa, G. (2003). Shift work and occupational medicine: An overview. Occupational Medicine. 53, 83-88. doi:10.1093/occmed/kqg045

Custers, K., \& Van den Bulck, J. (2012). Television viewing, internet use, and self-reported bedtime and rise time in adults: Implications for sleep hygiene recommendations from an exploratory cross-sectional study. Behavioral Sleep Medicine, 10(2), 96-105. doi:10.1080/15402002.2011.596599

DeYoung, C. G., Hasher, L., Djikic, M., Criger, B., \& Peterson, J. B. (2007). Morning people are stable people: Circadian rhythm and the higher-order factors of the big five. Personality and Individual Differences, 43, 267-276. doi:10.1016/j.paid.2006.11.030

Diaz-Morales, J.F., \& Sánchez-López, M.P. (2008). Morningness-eveningness and anxiety among adults: A matter of sex/gender?. Personality and Individual Differences 44, 1391-1401. doi:10.1016/j.paid.2007.12.007

Digdon, N. L., \& Rhodes, S., (2009). Methods used to cope with sleepiness may perpetuate sleepiness in college students with an evening type circadian preference. Biological Rhythm Research. 40, 129-144. doi:10.1080/09291010801987700

Dinzeo, T. J., Thayasivam, U., \& Sledjeski, E. M. (2014). The development of the lifestyle and habits questionnairebrief version: Relationship to quality of life and stress in college students. Prevention Science, 15, 103-114. doi:10.1007/s11121-013-0370-1

Eliasson, A. H., Lettieri, C. J., \& Eliasson, A. H. (2010). Early to bed, early to rise! Sleep habits and academic performance in college students. Sleep and Breathing, 14, 71-75. doi:10.1007/s11325-009-0282-2

Felix, V. A., Gremillion, M., \& Buboltz, W. (2015). Social media and mobile phone use: Relationship to sleep quality and length. In A. M. Columbus (Ed.), Advances in Psychology Research: Vol. 104. Hauppauge, NY: Nova Science Publishers.

Fernandez-Mendoza, J., Ilioudi, C., Montes, M. I., Olavarrieta-Bernardino, S., Aguirre-Berrocal, A., De La Cruz-Troca, J. J., \& Vela-Bueno, A. (2010). Circadian preference, nighttime sleep and daytime functioning in young adulthood. Sleep and Biological Rhythms, 8, 52-62. doi:10.1111/j.1479-8425.2010.00430.x

Forquer, L. M., Camden, A. E., Gabriau, K. M., \& Johnson, C. M. (2008). Sleep patterns of college students at a public university. Journal of American College Health, 56, 563-565. doi:10.3200/jach.56.5.563-565

Galambos, N. L., Dalton, A. L., \& Maggs, J. L. (2009). Losing sleep over it: Day variation in sleep quantity and quality in Canadian students' first semester of university. Journal of Research on Adolescence, 19, 741-761.

doi:10.1111/j.1532-7795.2009.00618.x 
Gaultney, J. F. (2010) The prevalence of sleep disorders in college students: Impact on academic performance. Journal of American College Health, 59, 91-97. doi:10.1080/07448481.2010.483708

Gellis, L. A., Park, A., Stotsky, M. T., \& Taylor, D. J. (2014). Associations between sleep hygiene and insomnia severity in college students: Cross-sectional and prospective analyses. Behavior Therapy, 45, 806-816. doi:10.1016/j.beth.2014.05.002

Gianotti, F., Cortesi, F., Sebastiani, T., \& Ottaviano, S. (2002). Circadian preference, sleep and daytime behaviour in adolescence. Journal of Sleep Research. 11, 191-199. doi:10.1046/j.1365-2869.2002.00302.x

Gilbert, S. P., \& Weaver, C. C. (2010). Sleep quality and academic performance in university students: A wake-up call for college psychologists. Journal of College Student Psychotherapy, 24, 295-306.

doi:10.1080/87568225.2010.509245

Gress-Smith, J. L., Roubinov, D. L., Andreotti, C., Compas, B. E., \& Luecken, L. J. (2015). Prevalence, severity and risk factors for depressive symptoms and insomnia in college undergraduates. Journal of the International Society for the Investigation of Stress, 31, 63-70. doi:10.1002/smi.2509

Gropper, S. S., Newell, F. H., Zaremba-Morgan, A., Keiley, M. K., White, B. D., Huggins, K. W. . Ulrich, P. V. (2012). The impact of physical activity on body weight and fat gains during the first 3 years of college. International Journal of Health Promotion and Education, 50, 296-310. doi:10.1080/14635240.2012.724190

Holbrook, A. M., Crowther, R., Lotter, A., Cheng, C., \& King, D. (2000). Meta-analysis of benzodiazepine use in the treatment of insomnia. CMAJ: Canadian Medical Association Journal, 162, 225-233.

Howell, A. J., Jahrig, J. C., \& Powell, R. A. (2004). Sleep quality, sleep propensity, and academic performance. Perceptual and Motor Skills, 99, 525-535. doi:10.2466/pms.99.2.525-535

Jackson, L. A., \& Gerard, D. A. (1996). Diurnal types, the "big five" personality factors, and other personal characteristics. Journal of Social Behavior Personality. 11, 273-284.

Kenney, S., Labrie, J., Hummer, J., \& Pham, A. (2012). Global sleep quality as a moderator of alcohol consumption and consequences in college students. Addictive Behaviors, 37, 507-512. doi:10.1016/j.addbeh.2012.01.006

Kredlow, M. A., Capozzoli, M. C., Hearon, B. A., Calkins, A. W., \& Otto, M. W. (2014). The effects of physical activity on sleep: A meta-analytic review. Journal of Behavioral Medicine, 38, 427-449. doi:10.1007/s10865-015-9617-6

LeBlanc, M., Beaulieu-Bonneau, S., Mérette, C., Savard., J., Ivers, H., \& Morin, C. M. (2007). Psychological and healthrelated quality of life factors associated with insomnia in a population-based sample. Journal of Psychosomatic Research, 63, 157-166. doi:10.1016/j.jpsychores.2007.03.004

Lee, S., Wuertz, C., Rogers, R., \& Chen, Y. (2013). Stress and sleep disturbances in female college students. American Journal of Health Behavior, 37, 851-858. doi:10.5993/AJHB.37.6.14

Lohsoonthorn, V., Khidir, H., Casillas, G., Lertmaharit, S., Tadesse, M., Pensuksan, W., \& ... Williams, M. (2013). Sleep quality and sleep patterns in relation to consumption of energy drinks, caffeinated beverages, and other stimulants among Thai college students. Sleep \& Breathing, 17, 1017-1028. doi:10.1007/s11325-012-0792-1

Lund, H. G., Reider, B. D., Whiting, A. B., \& Prichard, J. (2010). Sleep patterns and predictors of disturbed sleep in a large population of college students. Journal of Adolescent Health, 46, 124-132.

doi:10.1016/j.jadohealth.2009.06.016

Matthews, G. (1986). The effects of anxiety on intellectual performance: When and why are they found?. Journal of Research in Personality, 20, 385-401. doi:10.1016/0092-6566(86)90121-2

Mayo Clinic Staff (2014). Diseases and Conditions: Insomnia. Retrieved from http://www.mayoclinic.org/diseases-conditions/insomnia/basics/causes/con-20024293

Mecacci, L., \& Rocchetti, G. (1998). Morning and evening types: Stress-related personality aspects. Personality and Individual Differences. 25, 537-542. doi:10.1016/s0191 8869(98)00087-7 
Monk, T. H., Buysse, D. K., Potts, J. M., DeGrazia, J. N., \& Kupfer, D. J. (2004). Morningness-eveningness andlifestyle regularity. Chronobiology International , 21, 435-443. doi:10.1081/cbi-120038614

Morin, C.M., Kowatch, R.A., Barry, T., Walton E. (1993). Cognitive-behaviour therapy for late-life insomnia. Journal of Consulting Clinical Psychology, 61(1), 137- 46. doi:10.1037/0022-006x.61.1.137

National Sleep Foundation (2005). 2005 Sleep in America poll. Retrieved from National Sleep Foundation website: https://sleepfoundation.org/sites/default/files /2005_summary_of_findings.pdf

National Sleep Foundation (2015). National sleep foundation recommends new sleep durations. Retrieved from https://sleepfoundation.org/media-center/press-release/national-sleep-foundation-recommends-new-sleeptimes.

Nebel, L. E., Howell, R. H., Krantz, D. S., Falconer, J. J., Gottdiener, J. S., \& Gabbay, F. H. (1996). The circadian variation of cardiovascular stress levels and reactivity: Relationship to individual differences in morningness/eveningness. Psychophysiology, 33, 273-281. doi:10.1111/j.1469-8986.1996.tb00424.x

Orzech, K. M., Salafsky, D. B., \& Hamilton, L. A. (2011). The state of sleep among college students at a large public university. Journal of American College Health, 59, 612-619. doi:10.1080/07448481.2010.520051

Randler, C. (2007). Morningness-eveningness and satisfaction with life. Social Indicators Research, 86, $297-302$. doi:10.1007/s11205-007-9139-x

Roane, B. \& Taylor, D. J. (2008). Adolescent insomnia as a risk factor for early adult depression and substance abuse. Sleep, 31, 1351-1356.

Sadigh, M. R., Himmanen, S. A., Scepansky, JA. (2014). An investigation of the prevalence of insomnia in college students and its relationship to trait anxiety. College Student Journal, 48, 397-406.

Schneider, M. L., Vasconcellos, D.C., Dantas, G., Levandovski, R., Caumo, W., Allebrandt, K. V., \& Hidalgo, M. P. (2011). Morningness-eveningness, use of stimulants, and minor psychiatric disorders among undergraduate students. International Journal of Psychology, 46, 18-23. doi:10.1080/00207594.2010.513414

Singleton, R. A.,Jr, \& Wolfson, A. R. (2009). Alcohol consumption sleep, and academic performance among college students. Journal of Studies on Alcohol and Drugs, 70, 355-363. doi:10.15288/jsad.2009.70.355.

Stasio, M. J., Curry, K., Wagener, A. L., \& Glassman, D. M. (2011). Revving up and staying up: Energy drink use associated with anxiety and sleep quality in a college sample. College Student Journal, 45, 738-748. Retrieved from: https://www.questia.com/library/journal/ 1G1-278276697/revving-up-and-staying-up-energy-drink-useassociated

Stewart, R., Besset, A., Bebbington, P., Brugha, T. Lindesay, J., Jankins, R,...Meltzer, H. (2006). Insomnia comorbidity and impact and hypnotic use by age group in a natural survey population aged 16 to 74 years. Sleep, 29(11), 13911397. Retrieved from: http://www.journalsleep.org/Default.aspx

Suen, L. K. P., Ellis Hon, L. K., \& Tam, W. W. S. (2008). Association between sleep behavior and sleep-related factors among university students in Hong Kong. Chronobiology International, 25, 760-775. doi:10.1080/07420520802397186

Taillard, J., Philip, P., Chastang, J. F., Diefenbach, K., \& Bioulac, B. (2001). Is self-reported morbidity related to the circadian clock? Journal of Biological Rhythms, 16, 183-190. doi:10.1177/074873001129001764

Takeuchi, H., Morisane, H., Iwanaga, A., Hino, N., Matsuoka, A., \& Harada, T. (2002). Morningness-eveningness preference and mood in Japanese junior high school students. Psychiatry and Clinical Neurosciences. 56, 227-228. doi:10.1046/j.1440-1819.2002.00985.x

Taylor, D. J., Bramoweth, A. D., Grieser, E. A., Tatum, J. I., \& Roane, B. M. (2013). Epidemiology of insomnia in college students: Relationship with mental health, quality of life, and substance difficulties. Behavior Therapy, 44, 339-348. doi:10.1016/j.beth.2012.12.001 
Taylor, D. J., Clay, K. C., Bramoweth, A. D., Sethi, K., \& Roane, B. M. (2011). Circadian phase preference in college students: Relationships with psychological functioning and academics. Chronobiology International, 28, 541-547. doi:10.3109/07420528.2011.580870

Trockel, M. T., Barnes, M. D., \& Egget, D. L. (2000). Health-related variables and academic performance among first-year college students: Implications for sleep and other behaviors. Journal of American College Health, 49, 125131. doi:10.1080//07448480009596294

Van den Bulck, J. (1999). VCR-use and patterns of time shifting and selectivity. Journal of Broadcasting \& Electronic Media, 43(3), 316-326. doi:10.1080/08838159909364494

Weitzman, E. D., Czeisler, C. A., Coleman, R. M., Spielman, A. J., Zimmerman, J. C, Dement, W., \& Pollak, C. P. (1981). Delayed sleep phase syndrome: A chronobiological disorder with sleep-onset insomnia. Archives of General Psychiatry, 38, 737-746. doi:10.1001/archpsyc.1981.01780320017001

Willis, T. A., O'Connor, D. B., \& Smith, L. (2005). The influence of morningness-eveningness on anxiety and cardiovascular responses to stress. Physiology and Behavior, 85, 125-133. doi:10.1016/j.physbeh.2005.03.013

White, A. G., Buboltz, W. C., Jr., \& Frank, I. (2011). Mobile phone use and sleep quality and length in college students. International Journal of Humanities and Social Science, 1, 51-58.

Wu, X., Tao, S., Zhang, Y., \& Tao, F. (2015). Low physical activity and high screen time can increase the risks of mental health problems and poor sleep quality among Chinese college students. PLoS One, 10(3). Retrieved from: http://journals.plos.org/plosone/ article?id=10.1371/journal.pone.0119607

Zawadzki, M. J., Graham, J. E., \& Gerin, W. (2013). Rumination and anxiety mediate the effect of loneliness on depressed mood and sleep quality in college students. Health Psychology, 32, 212-222. doi:10.1037/a0029007

Zimmermann, L. K. (2011). Chronotype and the transition to college life. Chronobiology International, 28, 904-910. doi:10.3109/07420528.2011.618959 